\title{
An exploratory analysis to determine the impact of fixed effects and to establish genetic parameters across six types of ostrich feathers
}

\author{
Z. Brand ${ }^{1 \#}$ \& S.W.P. Cloete ${ }^{2,3}$ \\ ${ }^{1}$ Directorate: Animal Sciences, Department of Agriculture Western Cape, PO Box 351, Oudtshoorn, 6220, South Africa \\ ${ }^{2}$ Directorate: Animal Sciences, Department of Agriculture Western Cape, Private Bag X1, Elsenburg, 7607, South Africa \\ ${ }^{3}$ Department of Animal Sciences, University of Stellenbosch, Private Bag X1, Matieland, 7602, South Africa
}

(Received 19 March 2014; Accepted 10 February 2015; First published online 24 February 2015)

Copyright resides with the authors in terms of the Creative Commons Attribution 2.5 South African Licence.
See: http://creativecommons.org/licenses/by/2.5/za
Condition of use: The user may copy, distribute, transmit and adapt the work, but must recognise the authors and the South African
Journal of Animal Science.

\begin{abstract}
After a decline in value, ostrich feathers have again become an important part of the income of ostrich producers. Between 22586 and 22753 feather weights, as well as length and width measurements, were obtained from feathers harvested annually during the resting period from a pair-bred ostrich flock maintained at Oudtshoorn Research Farm from 2001 to 2012. The flock consisted mostly of the South African Black (SAB) genotype, but birds from the Zimbabwean Blue (ZB) and Kenyan Redneck (KR) strains were also introduced to study strain effects, as well as the effect of crossbreeding between these genotypes ( $Z B X$ $\mathrm{SAB}$; SAB $\times$ ZB; KR $\times$ SAB; SAB $\times \mathrm{KR}$ ). The feathers were sorted into six feather-type categories, namely floss, short hard body feathers, long hard body feathers, tail feathers, white plumes and short body floss. White plumes had the highest average feather length (AFL), average feather width (AFWD) and square-roottransformed feather weight (SRFW) at $66.2 \pm 0.38 \mathrm{~cm}, 21.2 \pm 0.23 \mathrm{~cm}$ and $13.66 \pm 0.17 \mathrm{~g}$, respectively. A significant decline in AFL took place from 2001 and $2012(40.0 \pm 0.25 \mathrm{~cm}$ and $38.7 \pm 0.56 \mathrm{~cm}$, respectively), while AFWD stayed fairly constant. Feather weights were higher for males than females resulting in a $24 \%$ higher geometric mean for backtransformed feather weights (GMFW) for males relative to females. SAB birds outperformed ZB and KR birds for AFL, AFWD and SRFW. Crosses were intermediate and sometimes comparable with the SAB genotype. Except for long hard body plumes, the weights for all the feather types were higher for the purebred SAB breeders compared with purebred ZB and KR breeders. Heritability estimates of AFL, AFWD and SRFW across the six feather categories were low to moderate at $0.080 \pm$ $0.012,0.044 \pm 0.009$ and $0.116 \pm 0.017$, respectively. The animal permanent environmental effect for the feather traits was lower in magnitude and ranged between $0.025 \pm 0.008$ for AFL and $0.041 \pm 0.012 \mathrm{~cm}$ for SRFW. Direct genetic correlations of feather dimensions with SRFW were moderate to high at $0.287 \pm 0.117$ with AFL and $0.614 \pm 0.072$ with AFWD. The present results indicate that feather quantity can be improved by genetic selection in ostriches, and further studies should be conducted.
\end{abstract}

Keywords: Age, feather length, feather weight, feather width, genotype, sex

\#Corresponding author: zanellb@elsenburg.com

\section{Introduction}

For centuries, the demand for ostrich feathers was met by killing ostriches, with no attempt to develop a non-lethal method of harvesting (Deeming, 1999). Ostrich farming started between 1857 and 1864, when ostriches were taken into captivity to produce feathers for fashion items (Smit, 1963). It became a commercial enterprise in South Africa and has been an important contributor to the regional agricultural economy of the Klein Karoo for the past 150 or so years. Initially, ostrich feathers were the main commercial product and were highly prized by the European fashion industry. Crossbreeding and strict selection for feather quality were carried out about a century ago, resulting in the South African Black (SAB) strain (Swart, 1979), which became synonymous with feather production and feather quality.

During World War I (1914 to 1918), the South African ostrich feather industry collapsed (Smit, 1963). In the following years, the industry recovered, but the skin and meat became the more dominant sources of income. Research on the improvement of the quality or quantity of ostrich feathers thus stopped. Swart et al. (1984) assessed the impact of feather quality traits on price determination in the marketplace. Because of 
the lower importance of feathers to the income of ostrich farmers since 1975, scientific selection programmes on feather quality have not been implemented.

Genetic make-up is one of the factors that influence the performance of individuals and genetic improvement may be achieved by selection for specific traits (Petitte \& Davis, 1999). In the past few decades, extensive breeding research has been carried out to improve production traits in common domestic livestock species. Access to information on genetic and crossbreeding parameters, as well as line and breed differences, ensures structured breeding programmes, involving line- and crossbreeding and exploiting sexual dimorphism and heterosis. Crossbreeding has long been recognised as an effective method of improving on-farm productivity of commercial livestock through the exploitation of heterosis, with heterosis being defined as the difference in the mean performance between crossbreds and the mid-parent value of their parental breeds (Cartwright \& Hammack, 1982). However, knowledge about genetic parameters and responses to selection for specific traits is still limited in the ostrich industry. Definite breeding objectives and industry breeding structures are still largely absent in the commercial ostrich industry (Cloete et al., 2002; 2008). Limitations typical of ostrich production systems also present challenges to implementing genetic improvement programmes (Cloete et al., 1998; 2002; Bunter, 2002).

The objective of this study was therefore to do an exploratory analysis involving the impact of fixed effects on the various feather types of commercial value and to estimate genetic parameters for quantitative feather traits of ostriches.

\section{Material and Methods}

The experimental population for the study (2001 - 2012) was the commercial, pair-bred ostrich breeding flock at Oudtshoorn Research Farm of the Western Cape Department of Agriculture in the Klein Karoo region of South Africa. The origin of the flock and general management procedures have been described by Cloete et al. (1998; 2008) and Bunter \& Cloete (2004). The flock consisted mostly of birds of the South African Black (SAB) genotype, but birds from the Zimbabwean Blue (ZB) (Engelbrecht et al., 2008) and Kenyan Redneck (KR) (Davids, 2011) strains were introduced to study crossbreeding between these genotypes. Purebred SAB and ZB birds were available throughout the experimental period and the number of available annual feather records ranged from 624 to 1776 and from 18 to 341, respectively. The reciprocal cross between the latter breeds was present from 2005 to 2012. Between 53 and 411 annual records were available for ZB $\times$ SAB birds and between 6 and 89 annual records for SAB $\times$ ZB birds. KR birds were present from 2007 to 2012 and were represented by 99 - 206 annual records. Between 12 and 52 annual records represented the $K R \times S A B$ genotype from 2009 to 2012, while the $S A B \times K R$ genotype was represented by 6 - 30 annual records from 2010 to 2012 .

The flock consisted of 136 to 188 breeding pairs and the age of breeder birds in the flock ranged from 2 to 14 years. The annual breeding season usually lasted about eight months (from mid-May to January the following year) followed by a four-month rest period. During the annual resting period, feathers were harvested, sorted, categorized and weighed, ensuring repeated animal-year records for the mature breeding birds in the flock at that stage. The feather categories were the six feather types (definitions following each category) harvested from the ostrich, namely floss: one row of soft downy feathers under the wing, short hard body feathers; SHB: feathers in the centre of the dorsal surface of the wing just before long hard feathers, long hard body feathers; LHB: second and third row of feathers on the outer edge of the wing, tail feathers, white plumes; WP: first row of prominent plumes at the edge of the wing) and short body floss; SBF: feathers under the wing and on the front and back of the thigh. The feather types were weighed and measured on 10 representative feathers per category to derive average feather length (AFL) and average feather width (AFWD) for individual birds. All feather weights were extremely variable, and the data were therefore subjected to a square root transformation to stabilize the variances. Square-root-transformed feather weights (SRFW) were backtransformed to geometric means for the feather weights (GMFW).

Estimation of the genetic parameters was done with ASREML (Gilmour et al., 2009), first by fitting a single-trait animal model to each trait. Fixed effects included production year (12), sex (2), animal age (encompassing 13 classes from 2 to 14 years) and genotype (SAB, ZB, KR and their reciprocal crosses). Random effects fitted to each trait included the direct additive effect of unique animal, the animal permanent environmental effects modelling unique animal records across years, as well as the effect of unique animal records within a year across the defined body locations (subsequently labelled animal temporary environmental effects). These combinations resulted in the following three models in matrix notation:

$$
\begin{aligned}
& \mathbf{y}=X \mathbf{b}+Z_{1} \mathbf{a}+\mathbf{e} \\
& \mathbf{y}=X \mathbf{b}+Z_{1} \mathbf{a}+Z_{2} \mathbf{p e}+\mathbf{e} \\
& \mathbf{y}=X \mathbf{b}+Z_{1} \mathbf{a}+Z_{2} \mathbf{p e}+Z_{3} \mathbf{t e}+\mathbf{e}
\end{aligned}
$$


where $\mathbf{y}$ is a vector of observed traits in animals; $\mathbf{b}, \mathbf{a}$, pe and te are vectors of fixed effects, direct additive effects, animal permanent environmental effects and animal temporary environmental effects, respectively; $X, Z_{1}, Z_{2}$ and $Z_{3}$ are incidence matrices relating fixed effects, direct additive effects, animal permanent environmental effects, and animal temporary environmental effects to $\mathbf{y}$, respectively, and $\mathbf{e}$ is the vector of residuals.

It was assumed that $\mathrm{V}(\mathrm{a})=\mathrm{A} \sigma^{2}$; $\mathrm{V}(\mathrm{pe})=\mathrm{I} \sigma_{\mathrm{pe}}^{2} ; \mathrm{V}(\mathrm{te})=\mathrm{I} \sigma_{\mathrm{te}}^{2} ; \mathrm{V}(\mathrm{e})=\mathrm{I} \sigma_{\mathrm{e}}^{2}$, where $\mathrm{A}$ is the numerator relationship matrix, I are identity matrices, $\sigma_{a}^{2}, \sigma_{\text {pe }}^{2}, \sigma_{\text {te }}^{2}$ and $\sigma_{\text {e }}^{2}$ are the direct additive variance, animal permanent environmental variance, animal temporary environmental variance and environmental variance, respectively. All components, with the phenotypic variance $\left(\sigma_{p}^{2}\right)$, being the sum of $\sigma^{2}$, $\sigma_{\text {pe }}^{2}, \sigma_{\text {te }}^{2}$, and $\sigma^{2}$, were derived at the convergence of the log likelihood in the models, as well as the parameters.

The determination of the most suitable model to estimate (co)variance components for each trait was done with log likelihood ratio tests. The inclusion of a random effect was considered significant when the log likelihood value improved significantly compared with a model where the effect was not included. This improvement was determined when the statistic $-2\left(\log L_{2}-\log L_{1}\right)$ was greater than values of the chi-square distribution of $\alpha=0.05$ (3.84) at one degree of freedom (Swalve, 1993). This was to determine the most suitable model for each trait with the lowest possible number of random effects. The pedigree file contained 4909 animals with 490 sires and 506 dams, traced back over seven generations.

The genetic, permanent environmental, environmental and phenotypic correlations between traits were estimated using a three-trait animal model in ASREML (Gilmour et al., 2009). The (co)variance components obtained with the initial single-trait models were used as starting values for the three-trait models using the best model for each trait.

\section{Results and Discussion}

Descriptive statistics in Table 1 shows marked variation for each of the feather traits. The number of feather records for the various traits ranged from 22753 to 22786 . AFL and AFWD amounted to $41 \mathrm{~cm}$ and $16 \mathrm{~cm}$, respectively, with high coefficients of variation (CV) of between $33.3 \%$ and 36.1\%. Untransformed feather weight was $108 \mathrm{~g}$, with a very high CV of 67.7\%, while the SRFW amounted to $9.7 \mathrm{~g}$, with a CV of $38 \%$. Comparable estimates were not found in the literature for feather weights of ostriches differentiated according to commercial classes.

The effect of feather type on the AFL, AFWD, SRFW and GMFW is shown in Table 2. There is considerable variation among the six feather categories. White plumes had the highest AFL (66.2 cm), AFWD $(21.2 \mathrm{~cm})$, SRFW $(13.7 \mathrm{~g})$ and GMFW $(186.6 \mathrm{~g})$. The white plumes are regarded as the most valuable feather type, resulting from high demand from the fashion industry abroad (Swart, 1979). Apart from the floss, the tail feathers have the lowest overall values. These feathers are usually in a bad condition when harvested, because of wear and tear during the breeding season.

There was a significant $(P<0.05)$ decline in AFL from 2001 to $2012(40.0 \mathrm{~cm}$ and $38.7 \mathrm{~cm}$, respectively), while AFWD stayed fairly constant over the 12 years (Table 3). SRFW and GMFW showed the same trend as AFL with significant differences that occurred between years, with the highest GMFW in 2001 (98.2 g) and the lowest in 2011 (67.8 g). Possible explanations for the decline in both AFL and GMFW are that the main selection strategy for the flock was for reproduction and liveweight (Cloete et al., 2008) and not explicitly for feather traits. There was also a proportional increase in KR birds and crosses involving this genotype with generally inferior feather characteristics (see Material and Methods). Direct selection for any of these feather categories has not occurred in the past 12 years.

Table 1 Descriptive statistics for ostrich feather traits, pooled across six feather types

\begin{tabular}{lccc}
\hline Trait & $\begin{array}{c}\text { Number of } \\
\text { observations }\end{array}$ & Mean \pm s.d. & CV\% \\
\hline AFL $(\mathrm{cm})$ & 22753 & $40.97 \pm 14.81$ & 36.1 \\
AFWD (cm) & 22753 & $15.97 \pm 5.32$ & 33.3 \\
AFW (g) & 22586 & $108.65 \pm 73.61$ & 67.7 \\
SRFW (g) & 22586 & $9.73 \pm 3.73$ & 38.3
\end{tabular}

SD: standard deviation; CV\%: coefficient of variation; AFL, average feather length;

AFWD: average feather width; AFW: average feather weight;

SRFW: square-root-transformed feather weight. 
Table 2 Least squares means ( \pm S.E.) depicting the influence of ostrich feather type on average feather length (AFL), average feather width (AFWD) and square-root-transformed feather weight (SRFW)

Geometric means for backtransformed feather weights (GMFW) with estimated S.E.s are provided

\begin{tabular}{lccccc}
\hline \multirow{2}{*}{ Type of feathers } & \multicolumn{7}{c}{ Trait } & SRWW & GMFW \\
\cline { 2 - 6 } White plumes (WP) & $\mathbf{N}$ & AFL & AFWD & SRFW & \\
Floss & 3906 & $66.2 \pm 0.38$ & $21.2 \pm 0.23$ & $13.66 \pm 0.17$ & $186.6 \pm 4.73$ \\
Long hard bodies (LHB) & 3461 & $30.9 \pm 0.42$ & $12.1 \pm 0.26$ & $4.22 \pm 0.18$ & $17.8 \pm 1.57$ \\
Tail & 3903 & $47.7 \pm 0.38$ & $17.8 \pm 0.24$ & $9.26 \pm 0.17$ & $85.8 \pm 3.21$ \\
Short hard bodies (SHB) & 3691 & $35.7 \pm 0.41$ & $13.0 \pm 0.25$ & $8.56 \pm 0.18$ & $73.3 \pm 3.15$ \\
Short body floss (SBF) & 3769 & $29.8 \pm 0.41$ & $13.3 \pm 0.25$ & $9.97 \pm 0.18$ & $99.4 \pm 3.66$ \\
& 3845 & $28.5 \pm 0.38$ & $12.5 \pm 0.23$ & $9.36 \pm 0.17$ & $87.7 \pm 3.24$ \\
\hline
\end{tabular}

There were no differences in AFL and AFWD between male and female breeding birds. However, feather weights were higher for males than females for SRFW and GMFW (Table 4). This resulted in a 24\% higher GMFW for males relative to females (geometric means being 96.3 vs. $72.9 \mathrm{~g}$, respectively), which is slightly higher than the $20 \%$ sex difference previously reported (Brand \& Cloete, 2009).

Table 3 Least squares means ( \pm S.E.) depicting the influence of production year on average feather length (AFL), average feather width (AFWD) and square-root-transformed feather weight (SRFW) pooled across feather types for ostriches

Geometric means for backtransformed feather weights (GMFW) with estimated S.E.s are provided

\begin{tabular}{|c|c|c|c|c|c|}
\hline \multirow{2}{*}{ Production year } & \multicolumn{5}{|c|}{ Trait } \\
\hline & $\mathbf{N}$ & AFL & AFWD & SRFW & GMFW \\
\hline 2001 & 1200 & $40.0^{a} \pm 0.25$ & $14.7 \pm 0.14$ & $9.91^{a} \pm 0.16$ & $98.2^{a} \pm 3.22$ \\
\hline 2002 & 634 & $40.1^{a} \pm 0.25$ & $15.1 \pm 0.14$ & $8.91^{\mathrm{d}, \mathrm{e}} \pm 0.18$ & $79.4^{\mathrm{d}, \mathrm{e}} \pm 3.15$ \\
\hline 2003 & 1835 & $40.0^{a} \pm 0.25$ & $15.1 \pm 0.15$ & $9.13^{d} \pm 0.15$ & $83.3^{d} \pm 2.79$ \\
\hline 2004 & 2095 & $40.2^{a} \pm 0.26$ & $15.1 \pm 0.15$ & $9.16^{d} \pm 0.15$ & $83.9^{d} \pm 2.74$ \\
\hline 2005 & 2073 & $40.2^{a} \pm 0.26$ & $15.3 \pm 0.15$ & $9.11^{d} \pm 0.15$ & $83.0^{d} \pm 2.67$ \\
\hline 2006 & 2129 & $39.9^{a, b} \pm 0.27$ & $15.2 \pm 0.16$ & $9.51^{\mathrm{b}, \mathrm{c}} \pm 0.14$ & $90.4^{\mathrm{b}, \mathrm{c}} \pm 2.74$ \\
\hline 2007 & 2127 & $39.8^{a, b} \pm 0.28$ & $15.1 \pm 0.18$ & $9.34^{b, c, d} \pm 0.14$ & $87.2^{b, c, d} \pm 2.64$ \\
\hline 2008 & 2191 & $39.6^{a, b} \pm 0.30$ & $15.1 \pm 0.21$ & $9.67^{\mathrm{a}, \mathrm{b}} \pm 0.14$ & $93.5^{a, b} \pm 2.73$ \\
\hline 2009 & 2158 & $39.5^{a, b} \pm 0.41$ & $15.3 \pm 0.25$ & $9.27^{\mathrm{c}, \mathrm{d}} \pm 0.14$ & $86.0^{c, d} \pm 2.62$ \\
\hline 2010 & 2077 & $39.7^{a, b} \pm 0.53$ & $14.7 \pm 0.33$ & $9.11^{d} \pm 0.14$ & $82.9^{d} \pm 2.53$ \\
\hline 2011 & 1815 & $40.4^{\mathrm{ab}} \pm 0.81$ & $14.6 \pm 0.52$ & $8.23^{f} \pm 0.14$ & $67.8^{f} \pm 2.32$ \\
\hline 2012 & 2251 & $38.7^{b} \pm 0.56$ & $14.1 \pm 0.35$ & $8.73^{\mathrm{e}} \pm 0.14$ & $76.1^{\mathrm{e}} \pm 2.45$ \\
\hline
\end{tabular}

The interaction of sex with type of feather suggested non-uniform sex effects across the types of feathers (Figures $1 \mathrm{a}$ and $\mathrm{b}$ ). Expressed relative to means for females, SRFW means of male ostriches increased by between 10\% (long hard bodies and white plumes) and 20\% for short hard bodies when assessed on square-root-transformed data (Figure 1a). These differences were accentuated in GMFW means, ranging from $17 \%$ for long hard bodies to $35 \%$ for short hard bodies (Figure $1 \mathrm{~b}$ ). The only previous research on the difference in ostrich feather quantity between sexes was that by Louw \& Swart (1982), where they reported that males had $2.4 \%$ more wing quills than females. 
Table 4 Least squares means ( \pm S.E.) depicting the influence of sex on average feather length (AFL), average feather width (AFWD) and square-root-transformed feather weight (SRFW) pooled across feather types

Geometric means for back-transformed feather weights (GMFW) with estimated S.E.s are provided

\begin{tabular}{lccccc}
\hline \multirow{5}{*}{ Sex } & N & AFL & AFWD & SRFW & GMFW \\
\cline { 2 - 6 } & 11360 & $39.3 \pm 0.29$ & $15.3 \pm 0.17$ & $9.81^{\mathrm{a}} \pm 0.14$ & $96.3^{\mathrm{a}} \pm 2.83$ \\
Male & 11215 & $40.3 \pm 0.29$ & $14.6 \pm 0.17$ & $8.53^{\mathrm{b}} \pm 0.15$ & $72.9^{\mathrm{b}} \pm 2.48$ \\
Female & & & & & \\
\hline
\end{tabular}

${ }^{a, b}$ Values with different superscripts in columns differ significantly $(P<0.05)$.

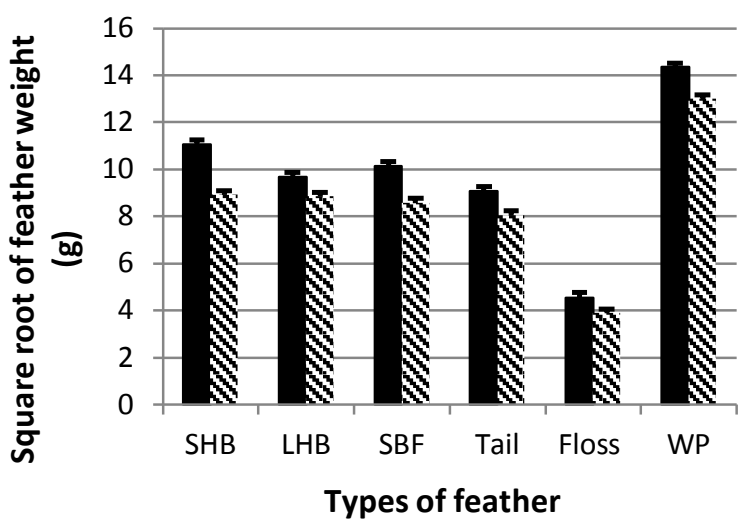

Types of feather

a

- Male sisemale

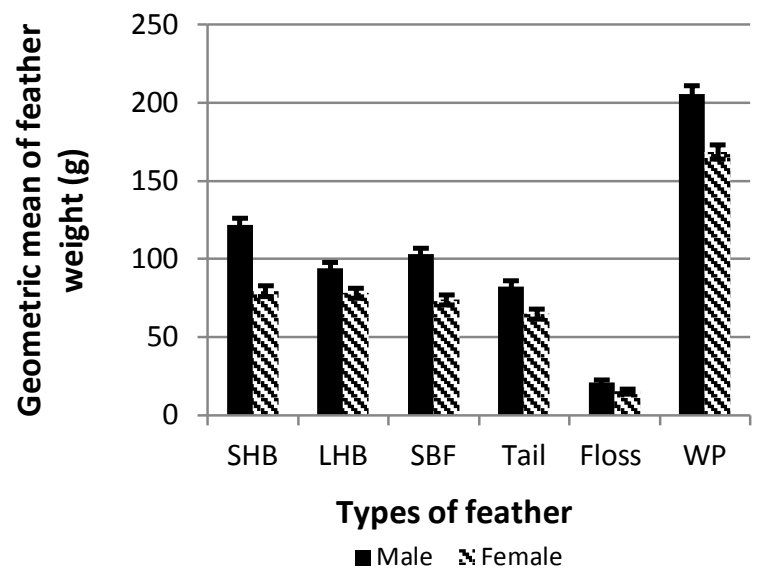

Figure 1 Means for different feather types of male and female ostriches for the square root of feather weights (a) and the geometric means of backtransformed values (b).

Vertical lines on the means depict standard errors.

Table 5 Number of observations for each of the male and female ostriches for the various ages

\begin{tabular}{lrrr}
\hline & Males & \multicolumn{2}{c}{ Females } \\
\hline Age & Number & Age & Number \\
\hline 2 & 1843 & 2 & 1987 \\
3 & 1816 & 3 & 1960 \\
4 & 1739 & 4 & 1746 \\
5 & 1643 & 5 & 1508 \\
6 & 1313 & 6 & 1236 \\
7 & 1131 & 7 & 1012 \\
8 & 895 & 8 & 835 \\
9 & 550 & 9 & 431 \\
10 & 221 & 10 & 252 \\
11 & 134 & 11 & 151 \\
12 & 68 & 12 & 62 \\
13 & 35 & 13 & 18 \\
14 & 82 & 14 & 79 \\
\end{tabular}


The number of observations per sex for the various age groups is shown in Table 5. The selection programme of the breeder flock involves choosing two-year-old breeders annually to replace older breeders in the flock. This advances the genetic improvement of the flock and contributes to the decrease in number of older animals.

Sex and animal age were found to interact $(P<0.05)$ for feather weight (Figures $2 a$ and $b)$. Feather weight generally followed the same age trend for male and female ostriches, with distinct sex differences being evident at all ages. A significant increase $(P<0.05)$ occurred in feather weight between the second and third years of production of both males (8\%) and females (12\%). Feather weight for both males and females increased with age, until it peaked at 6 years old $(104 \mathrm{~g}$ and $81 \mathrm{~g}$, respectively). Feather weights subsequently levelled off until the birds were about 11 years old. For both sexes, there was then a slight reduction in feather weight, but this decline was not significant. A sharp drop in feather production occurred between ages 12 and 13, but was not significant. The lower number of observations at higher ages is reflected in larger standard errors in this figure. Sampling could have contributed to the interaction of sex and animal age that mostly seemed to result from means at 12 and 13 years old. Since only three birds contributed to the mean for 13-year-old females (Table 5), sampling could be an issue. Deurden (1910) had previously reported that ostriches could produce good-quality feathers up to age 33 . The present results suggest that feather weights are likely to decline with advanced age beyond 12 years, although it would not be wise to speculate on what might happen at ages extrapolated beyond the recorded data.
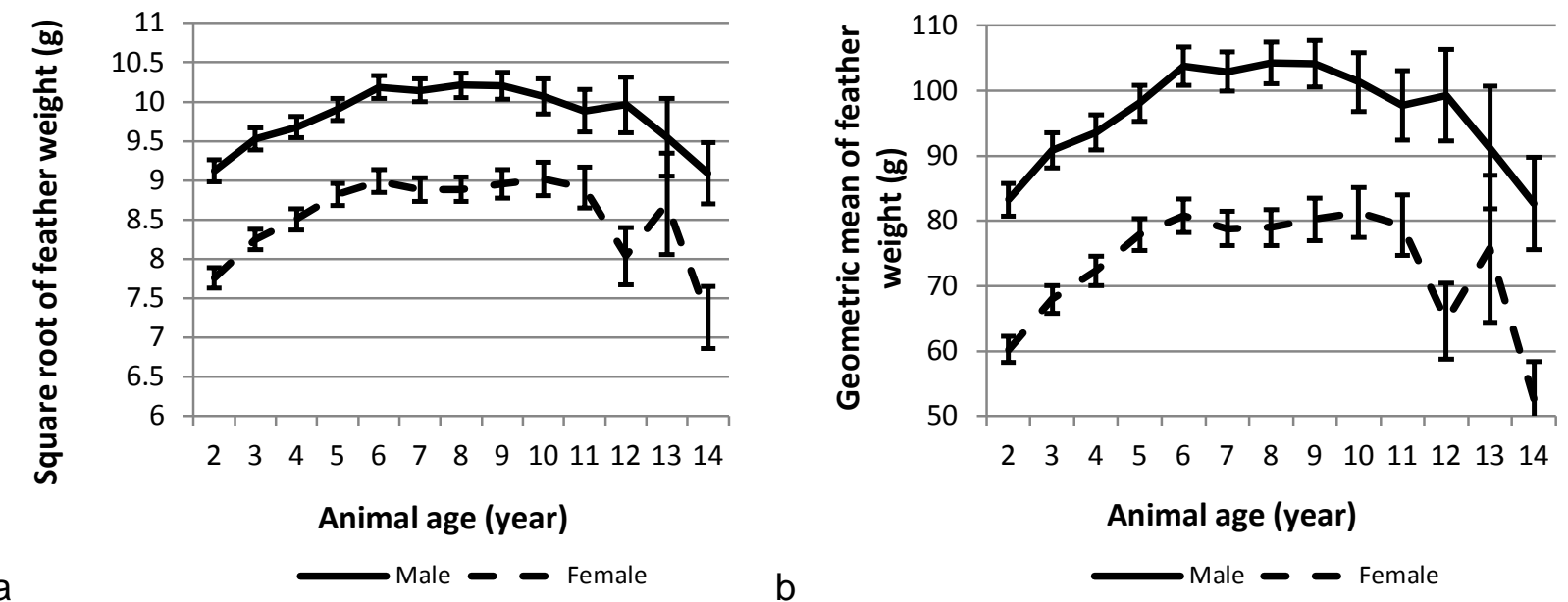

Figure 2 Trends depicting age effects for male and female ostriches for the square root of feather weights (a) and the geometric means of backtransformed values (b)

Vertical lines about the means depict standard errors.

South African Black (SAB) birds had significantly longer (3.4\%) feathers than ZB contemporaries, but AFL of the SAB strain did not differ significantly from that of pure KR birds as well as the crossbred combinations (Table 6). The SAB had greater feather width, ranging between $3 \%$ and $12 \%(P<0.05)$ compared with the ZB, ZB $\times$ SAB, KR, KR $\times$ SAB and SAB $\times$ KR strains. The exception was the SAB $\times$ ZB cross, with an AFWD similar to that of the SAB strain. ZB and KR pure breeds had the narrowest feathers at $14.2 \mathrm{~cm}$. The GMFW produced by SAB birds and the cross of ZB with SAB were between $19 \%$ and $27 \%$ higher $(P<0.05)$ than those of purebred $Z B$ and $K R$ birds, as well as the $S A B \times K R$ cross. However, $S A B$ feather weights did not differ from the other crosses with $S A B$ as one of the parents. These results for the $\mathrm{SAB}$ and $\mathrm{ZB}$ and their crosses are consistent with findings by Brand \& Cloete (2009). The lower number of observations for the KR $\times$ SAB and $S A B \times K R$ crosses is reflected in larger standard errors. In the breeding programme, the ZB strain was introduced to produce offspring with improved liveweight (Essa \& Cloete, 2006; Engelbrecht et al., 2008) and improved carcass weight (Brand et al. 2005). The purebred KR was introduced later for the same reasons (Davids, 2011). However, the effect of crossbreeding should be considered for other traits, including feathers. Results show that the pure SAB strain has superior feather characteristics compared with those of the purebred $\mathrm{ZB}$ and KR ostriches, with intermediate values for crosses of the SAB with the ZB and KR breeds. 
Table 6 Least squares means ( \pm S.E.) depicting the influence of the genotype of the animal on average feather length (AFL), average feather width (AFWD) and square-root-transformed feather weight (SRFW) for ostriches, pooled across feather types

Geometric means for backtransformed feather weights (GMFW) with estimated S.E.s are provided

\begin{tabular}{|c|c|c|c|c|c|}
\hline \multirow{2}{*}{ Genotype } & \multicolumn{5}{|c|}{ Trait } \\
\hline & $\mathrm{N}$ & AFL & AFWD & SRFW & GMFW \\
\hline SA Black (SAB) & 16729 & $40.5^{a} \pm 0.21$ & $16.0^{\mathrm{a}} \pm 0.12$ & $9.80^{a} \pm 0.11$ & $96.1^{a} \pm 2.10$ \\
\hline Zimbabwean Blue (ZB) & 2950 & $39.1^{b} \pm 0.24$ & $14.2^{\mathrm{c}} \pm 0.13$ & $8.80^{b} \pm 0.12$ & $77.5^{\mathrm{b}} \pm 2.12$ \\
\hline $\mathrm{ZB} \times \mathrm{SAB}$ & 1405 & $40.0^{a, b} \pm 0.29$ & $15.4^{\mathrm{b}} \pm 0.17$ & $9.68^{\mathrm{a}, \mathrm{b}} \pm 0.15$ & $93.6^{\mathrm{a}, \mathrm{b}} \pm 2.87$ \\
\hline$S A B \times Z B$ & 446 & $40.3^{\mathrm{a}, \mathrm{b}} \pm 0.44$ & $15.6^{\mathrm{a}, \mathrm{b}} \pm 0.26$ & $10.04^{a} \pm 0.23$ & $100.9^{a} \pm 4.56$ \\
\hline Kenyan Redneck (KR) & 885 & $39.7^{\mathrm{a}, \mathrm{b}} \pm 0.43$ & $14.2^{\mathrm{c}} \pm 0.24$ & $8.40^{\mathrm{b}} \pm 0.22$ & $70.6^{\mathrm{b}} \pm 3.63$ \\
\hline $\mathrm{KR} \times \mathrm{SAB}$ & 115 & $39.5^{a, b} \pm 0.76$ & $14.6^{\mathrm{b}, \mathrm{c}} \pm 0.45$ & $8.93^{a, b} \pm 0.38$ & $79.7^{\mathrm{a}, \mathrm{b}} \pm 6.81$ \\
\hline$S A B \times K R$ & 48 & $39.6^{\mathrm{a}, \mathrm{b}} \pm 0.99$ & $14.7^{\mathrm{b}, \mathrm{c}} \pm 0.60$ & $8.56^{b} \pm 0.50$ & $73.3^{\mathrm{b}} \pm 8.51$ \\
\hline
\end{tabular}

${ }^{a, b}$ Values with different superscripts in columns differ significantly $(P<0.05)$.

As shown in Figures $3 \mathrm{a}$ and $3 \mathrm{~b}$, the weights for all the feather types were generally higher $(P<0.05)$ for $S A B$ breeders compared with pure ZB breeders, long hard body plumes being the only exception. Excluding the weight of floss, the same trend occurred for the two crosses between SAB and ZB compared with the purebred ZB. Feather weights of the SAB strain mostly did not differ significantly from those of the two crosses with the ZB, with the exception again of long hard body plumes. The $S A B \times Z B$ cross produced up to $25 \%$ more LHB than the other genotypes (GMFW $=89.7 \mathrm{~g}$ and. $112.6 \mathrm{~g}$, respectively, for SAB and $\mathrm{SAB} \times \mathrm{ZB}$ ). Figure 3 shows that crossbred progeny mostly resembled the SAB genotype in crosses between the $S A B$ and $Z B$.

The weights for all the feather types were higher $(P<0.05)$ for $\mathrm{SAB}$ breeders compared with $\mathrm{KR}$ breeders, floss being the only exception (Figures $4 a$ and $b$ ). If assessed against the SAB and KR crosses, the feather weights for both SHB and SBF were significantly higher $(P<0.05)$ for the SAB, while no differences $(P>0.05)$ occurred between the weights of the other four feather types (LHB, tail, floss, white plumes). In contrast to the results reported for the $S A B$ and $Z B$, crosses between the $S A B$ and KR mostly resembled the KR in Figure 4. Neither of these results could be verified in the literature, as the present study is the first to report on differences between breeds and breed combinations.

These results indicate clear breed differences in feather production, with the SAB outperforming its ZB and KR contemporaries, while the crossbred progeny derived from the $Z B$ as one parent resembled the $S A B$ breed in terms of feather weights, and showed marked improvement from their pure ZB parents.

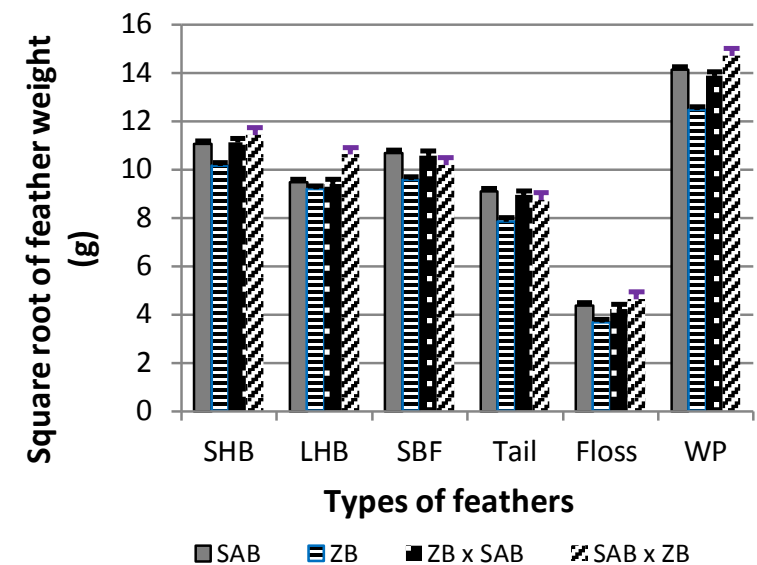

a them) for the square root of feather weights (a) and the geometric means of backtransformed values (b). Vertical lines on the means depict the standard errors. 

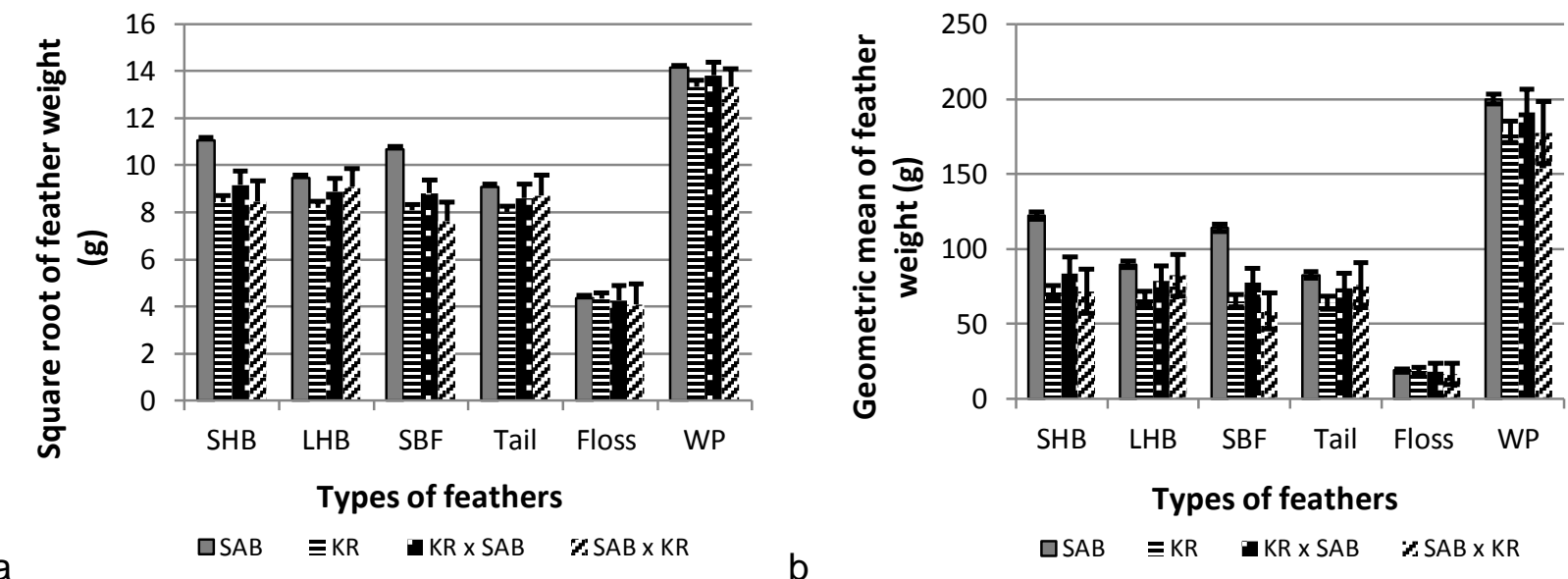

Figure 4 Means for feather types of various ostrich genotypes (SAB, KR and the reciprocal cross between them) for the square root of feather weights (a) and the geometric means of backtransformed values (b). Vertical lines on the means depict the standard errors.

Estimates of genetic parameters from the three-trait analysis are presented in Table 7. Derived heritability $\left(h^{2}\right)$ estimates for the feather traits (AFL, AFWD and SRFW) were low to moderate, ranging from 0.044 to 0.116 . All $h^{2}$ estimates were significant (at least double the corresponding S.E.). The only previous indication that ostrich feather quantity may respond to selection was reported by Louw \& Swart (1982).

Table 7 Estimates $\left( \pm\right.$ S.E.) of direct heritability $\left(h^{2}\right)$, animal permanent environment $\left(p e^{2}\right)$, the residual variance component $\left(\sigma_{e}^{2}\right)$ and the phenotypic variance component $\left(\sigma_{p}^{2}\right)$ for feather traits (bold on the diagonal), as well as genetic $\left(r_{g}\right)$, animal permanent environment $\left(r_{p e}\right)$ residual $\left(r_{e}\right)$ and phenotypic $\left(r_{p}\right)$ correlations among the ostrich feather traits on the upper off-diagonal

The effect of animal temporary environment $\left(t e^{2}\right)$ was present only for SRFW

\begin{tabular}{|c|c|c|c|}
\hline Trait & AFL & AFWD & SRFW \\
\hline \multicolumn{4}{|c|}{ Genetic correlations ( $h^{2}$ in bold on diagonal) } \\
\hline AFL & $0.080 \pm 0.012$ & $0.386 \pm 0.105$ & $0.614 \pm 0.072$ \\
\hline AFWD & & $0.044 \pm 0.009$ & $0.287 \pm 0.117$ \\
\hline SRFW & & & $0.116 \pm 0.017$ \\
\hline \multicolumn{4}{|c|}{ Animal PE correlation ( $\mathrm{pe}^{2}$ in bold on diagonal) } \\
\hline AFL & $0.025 \pm 0.008$ & $0.729 \pm 0.125$ & $0.880 \pm 0.130$ \\
\hline AFWD & & $0.030 \pm 0.007$ & $0.832 \pm 0.149$ \\
\hline SRFW & & & $0.041 \pm 0.012$ \\
\hline \multicolumn{4}{|c|}{ Animal TE effect (SRFW only) } \\
\hline SRFW & & & $0.072 \pm 0.005$ \\
\hline \multicolumn{4}{|c|}{ Residual correlations $\left(\sigma^{2}\right.$ in bold on diagonal) } \\
\hline AFL & 25.0 & $0.427 \pm 0.006$ & $0.220 \pm 0.007$ \\
\hline AFWD & & 10.3 & $0.142 \pm 0.007$ \\
\hline SRFW & & & 3.98 \\
\hline \multicolumn{4}{|c|}{ Phenotypic correlations $\left(\sigma_{\mathrm{p}}^{2}\right.$ in bold on diagonal) } \\
\hline AFL & $27.9 \pm 0.3$ & $0.432 \pm 0.006$ & $0.270 \pm 0.008$ \\
\hline AFWD & & $11.1 \pm 0.1$ & $0.170 \pm 0.008$ \\
\hline SRFW & & & $5.15 \pm 0.07$ \\
\hline
\end{tabular}


Louw \& Swart (1982) reported that the number of wing quills had a heritability of 0.24 . These results suggested that genetic improvement could be achieved in feather quantity of ostriches. Animal permanent environmental effects $\left(p e^{2}\right)$ accounted for a proportion of between 0.025 and 0.041 of the phenotypic variation associated with the categories of feather traits (Table 7). The genetic correlations $\left(r_{\mathrm{g}}\right)$ between the feather traits AFL and AFW were moderate at $0.386 \pm 0.105$, implying that with selection for one trait, an improvement in the other trait will occur. Genetic correlations of SRFW with AFL and AFW were high to moderate at $0.614 \pm 0.072$ and $0.287 \pm 0.117$, respectively. Animal permanent environmental correlations $\left(r_{\text {pe }}\right)$ generally followed genetic correlations in sign, but were higher in magnitude, with the correlations of AFL with AFWD and SRFW, being $0.729 \pm 0.125$ and $0.880 \pm 0.130$ respectively. The $r_{\text {pe }}$ of AFW with SRFW amounted to $0.832 \pm 0.149$. The temporary environmental effect for SRFW, although low, was significant at $0.072 \pm 0.005$. There were weak to moderate residual correlations $\left(r_{\mathrm{e}}\right)$ between the feather traits, with the $r_{\mathrm{e}}$ between AFW and SRFW at $0.142 \pm 0.007$ and the $r_{\mathrm{e}}$ between AFL and AFW at $0.427 \pm 0.006$. The phenotypic correlations $\left(r_{p}\right)$ were similar in sign to $r_{\mathrm{e}}$ and ranged between $0.170 \pm 0.008$ and $0.432 \pm 0.006$.

\section{Conclusion}

This study indicated clear breed differences in feather characteristics for ostriches, with the $S A B$ outperforming its $\mathrm{ZB}$ and $\mathrm{KR}$ contemporaries, while the crossbred progeny resembled the $\mathrm{SAB}$ breed in terms of feather weights for SAB-ZB combinations. Results from this study confirm that feather quantity in ostriches is heritable, and would respond to directed selection. Moderate to high genetic correlations indicate that selection for specific categories of feather traits are likely to result in desired correlated responses in the other traits. Further research is needed to derive a feasible selection strategy for the genetic improvement of ostrich feather traits.

\section{Acknowledgements}

The authors are grateful for the support of those responsible for the recording of the data used in the present study and those involved in the husbandry of the flock.

\section{References}

Brand, M.M., Cloete, S.W.P., Hoffman, L.C. \& Muller, M., 2005. A comparison of live weights, body measurements and reproductive traits in Zimbabwean Blue ostriches (Struthio camelus australis) and South African Black ostriches (S. camelus var. domesticus). Ed: Carbajo, E., Proc. $3^{\text {rd }}$ Int. Ratite Sci. Sym. \& XII Wrld Ostrich Cong., Madrid, Spain. pp. 73-80.

Brand, Z. \& Cloete, S.W.P., 2009. Genetic parameters for feather weights of breeding ostriches. Proc. Assoc. Advmt. Amin. Breed. Genet. 18, 488-491.

Bunter, K.L., 2002. The gentic analisys of reproduction and production traits recorded for farmed ostriches (Struthio camelus). PhD thesis, University New England, Armidale, Australia.

Bunter, K.L. \& Cloete, S.W.P., 2004. Genetic parameters for egg-, chick- and live-weight traits recorded in farmed ostriches (Struthio camelus). Livest. Prod. Sci. 91, 9-22.

Cartwright, T.C. \& Hammack, S.P., 1982. Utilizing crossbreeding to increase net herd efficiency. Proc. $3^{\text {rd }}$ Conf. Assoc. Advmt. Anim. Breed. Genet. pp. 44-49.

Cloete, S.W.P., Van Schalkwyk, S.J. \& Brand, Z., 1998. Ostrich breeding - progress towards a scientifically based strategy. Proc. $2^{\text {nd }}$ Int. Ratite Cong, Oudtshoorn, South Africa. pp. 55-62.

Cloete, S.W.P., Bunter, K.L. \& Van Schalkwyk, S.J., 2002. Progress towards a scientific breeding strategy for ostriches. Proc. $7^{\text {th }}$ Wrld Cong. Gen. Appl. Livest. Prod. 30, 561-568. August, Montpellier, France.

Cloete, S.W.P., Brand, Z., Bunter, K.L. \& Malecki, I.A., 2008. Direct responses in breeding values to selection of ostriches for liveweight and reproduction. Aust. J. Exp. Agric. 48, 1314-1319.

Davids, A.H., 2011. Estimation of genetic distance and heterosis in three ostrich (Struthio camelus) breeds for the improvement of productivity. MSc thesis, University of Stellenbosch, Stellenbosch, South Africa.

Deeming, D.C., 1999. The Ostrich, Biology, Production and Health. Ed. Deeming, D.C., CABI Publishing. CAB International, Wallingford. pp. 1-11.

Deurden, J.E., 1910. Experiments with ostriches. XIII. The influence of nutrition, season and quilling on the feather crop. Agric. J. Cape of Good Hope 36, 19-32.

Engelbrecht. A., Cloete, S.W.P. \& Van Wyk, J.B., 2008. Direct heterosis for live weight and chick mortality in ostriches. Aust. J. Exp. Agric. 48, 1320-1325.

Essa, F. \& Cloete, S.W.P., 2006. Survival and growth of purebred South African Black and Zimbabwean Blue ostriches and their reciprocal cross. Proc. $7^{\text {th }}$ Wrld Cong. Gen. Appl. Livest. Prod. Bello Horizonte, Brazil. Communication 10-03. 
Gilmour, A.R., Gogel, B.J., Cullis, B.R. \& Thompson, R., 2009. ASReml User Guide Release 3.0. NSW Department of Industry and Investment. VSN International Ltd, Hemel Hempstead, HP1 1ES, UK www.vsni.co.uk.

Louw, J.H. \& Swart, D., 1982. Genetic variation in the number of quills on the wings of ostriches. S. Afr. J. Sci. 78, 455-456.

Petitte, J.N. \& Davis, G., 1999. Breeding and Genetics. In: The Ostrich - Biology, Production and Health. Ed: Deeming, D.C., CABI Publishing, CAB International, Wallingford: pp. 275- 292.

Smit, D.J.vZ., 1963. Ostrich Farming in the Little Karoo. Bulletin No. 358, Department of Agricultural Technical Services, Pretoria, South Africa.

Swalve, H.H., 1993. Estimation of direct and maternal (co)variance components for growth traits in Australian Simmental beef cattle. J. Anim. Breed. Genet. 110, 241-52.

Swart, D., 1979. Die kwantifisering van kwaliteitseienskappe van volstruisvere en die relatiewe ekonomiese belangrikheid daarvan. PhD. Agric thesis, University of Stellenbosch, South Africa.

Swart, D., Heydenrych, H. \& Poggenpoel, D.G., 1984. Die relatiewe ekonomiese belang van kwalitietseienskappe by volstruisvere. S. Afr. J. Anim. Sci. 14, 45-50. 